\title{
Maternal adverse childhood experiences and their association with preterm birth: secondary analysis of data from universal health visiting
}

Katie Hardcastle ${ }^{1}$, Kat Ford ${ }^{2 *}$ and Mark A. Bellis ${ }^{1,2}$

\begin{abstract}
Background: Being born before full gestation can have short-term and life-long health implications, yet it remains difficult to determine the risk of preterm birth among expectant mothers. Across different health settings, increasing attention is given to the health and behavioural consequences of adverse childhood experiences (ACEs) such as child abuse or neglect, or exposure to harmful household environments (e.g. in which caregivers abuse alcohol), and the potential value of understanding these hidden harms when supporting individuals and families. A large international evidence base describes the association between childhood adversity and early years outcomes for mothers and children. However, the relationship between maternal ACEs and preterm birth has received far less attention.

Methods: Secondary analysis was carried out on anonymised cross-sectional data from health visiting services in south and west Wales that had previously captured information on mothers'ACEs during routine contacts. Demographic data and information on mothers' health were extracted from the Healthy Child Wales Programme.

Results: Half of all mothers sampled had experienced at least one ACE, with a history of ACEs more common among younger, white British mothers and those residing in deprived areas. Preterm birth was significantly independently associated with retrospective reports of childhood sexual abuse (adjusted odds ratio $[A O R]=3.83,95 \%$ confidence interval $[C I]=1.19-12.32, p=0.025)$, neglect $(A O R=7.60,95 \% C l=1.81-31.97, p=0.006)$ and overall ACE exposure $(A O R=2.67,95 \% \mathrm{Cl}=1.14-6.23, p=0.024)$, with one in ten mothers (10.0\%) who experienced $\geq 4$ ACEs having preterm birth. Sub-analyses revealed a more pronounced relationship among mothers with no known chronic health conditions, with those with $\geq 4$ ACEs and no known chronic condition four times more likely to give birth preterm ( $\mathrm{AOR}=3.89,95 \% \mathrm{Cl}=1.40-10.80, p=0.009$ ).

Conclusions: Findings highlight the importance of the entire maternal experience. The experience of childhood adversity can have a lasting impact into and beyond the prenatal period, potentially increasing the risk of preterm birth, even among otherwise healthy women. Increasing our understanding of the potential perinatal outcomes associated with ACEs can help to inform how maternity services and partners offer trauma-sensitive support to mitigate some of the risks of early parturition, as well as target intergenerational cycles of adversity and poor health.
\end{abstract}

\footnotetext{
*Correspondence: k.ford@bangor.ac.uk

2 Public Health Collaborating Unit, School of Medical and Health Sciences,

Bangor University, Wrexham Technology Park, Wrexham LL13 7YP, UK

Full list of author information is available at the end of the article
} original author(s) and the source, provide a link to the Creative Commons licence, and indicate if changes were made. The images or other third party material in this article are included in the article's Creative Commons licence, unless indicated otherwise in a credit line to the material. If material is not included in the article's Creative Commons licence and your intended use is not permitted by statutory regulation or exceeds the permitted use, you will need to obtain permission directly from the copyright holder. To view a copy of this licence, visit http://creativecommons.org/licenses/by/4.0/. The Creative Commons Public Domain Dedication waiver (http://creativeco mmons.org/publicdomain/zero/1.0/) applies to the data made available in this article, unless otherwise stated in a credit line to the data. 
Keywords: Adverse childhood experiences, Child maltreatment, Childhood sexual abuse, Preterm birth, Maternal mental health

\section{Background}

In the UK, infants born before 37 weeks gestation are considered preterm or premature. Preterm birth may follow spontaneous onset of early labour or may be the result of an obstetric intervention intended to reduce the risk of continued pregnancy, to either the child and/ or the mother [1]. According to the Office for National Statistics, $7.8 \%$ of live births were considered preterm in England and Wales in 2019 [2] and preterm birth accounts for $35 \%$ of all neonatal death globally [3]. Risk factors for preterm birth include demographic variables such as the extremes of maternal age [4] or low socioeconomic status (SES) [5], health-harming behaviours and pre-existing health problems (e.g. maternal smoking [6] and obesity [7]), and pregnancy-related factors such as multiple gestation or intra-uterine infection [8]. However, in many instances, the cause of a preterm birth cannot be identified [9]. Birth before full gestation can have both short-term health implications, and negative impacts throughout the life course [10]. For example, the immune systems of preterm infants are immature, resulting in reduced innate and adaptive immunity [11]. Preterm birth is also known to increase the risk of a range of neurological disorders, including cerebral palsy, epilepsy and visual and cognitive impairment [12-14]. Whilst advances in perinatal care have significantly increased rates of survival [13], this often means families and healthcare services are left coping with the consequences of infants being born prematurely.

Increasingly, the potential impact of trauma and, in particular, historic or childhood experiences of chronic or toxic stress, on a range of perinatal outcomes has been considered [15-18]. Adverse childhood experiences (ACEs) is a collective term that refers to cumulative experiences of direct victimisation (e.g. physical or sexual abuse) or exposure to household dysfunction (e.g. a household member who abuses alcohol or is incarcerated) occurring during the first 18 years of life [19]. Established life course impacts of ACEs include increased risk of poor mental health, chronic health conditions such as type 2 diabetes and heart disease, and even early mortality [20-22]. Relationships between ACEs and subsequent development of health problems can be mediated by the presence or absence of resilience and other protective factors [23]. Although currently there is limited empirical evidence, plausible or theoretical links between ACEs and preterm birth have been suggested. These include both epigenetic and biological mechanisms [24], by which stress and inflammatory adaptive processes alter the brain, placenta and uterus, and thus the timing of parturition. Previous literature has examined the links between stress experienced in adulthood or during pregnancy and premature birth $[25,26]$. However, recently studies have started to explore the role of childhood stress such as ACEs on preterm birth. Findings from a recent systematic review highlight that the majority of studies on this topic ( $n=7 / 9$ identified studies) suggest ACEs increase the risk for preterm birth [18]. However, no studies from the UK were identified in the review. A small prospective cohort study of African American women found that a history of childhood stress (in mothers) resulting from interpersonal loss and/or physical danger was associated with preterm birth, even when controlling for adult stress [27]. Although this relationship was postulated to be mediated by maternal cortisol, causal pathways remain unclear. Traumatic childhood experiences may not directly lead to increased risk for preterm birth, mediated instead by health behaviours. For example, studies have demonstrated links between ACEs, maternal alcohol consumption and preterm birth $[28,29]$.

Better understanding of the risk factors for preterm birth is an important element in both developing universal preventative measures, and in identifying those who are already at increased risk and may require additional support. Primary prevention interventions for preterm birth include nutritional supplementation and lifestyle and behaviour changes (e.g. smoking cessation, reducing occupational fatigue [30, 31]). Currently, despite advances in the use of biomarkers and ultrasound techniques (e.g. for cervical measurement [32]), when pregnancy begins, health practitioners have limited predictive ability for the relative risk of preterm birth [33], making it difficult to target treatment (e.g. prophylactic interventions), antenatal management decisions or support to reduce maternal and fetal risks. Many individual riskscoring systems have not been subject to rigorous evaluation [34], and there are very few stress-related models to predict preterm birth [35]. Nevertheless, the likelihood is that a combination of tests may offer the best advances in clinical prediction [36].

Across a wide range of health and healthcare issues, new research and policy is now considering the application of ACE-informed approaches (e.g. [37]). In healthcare settings this includes health visiting (a universal service for families with children under the age of five 
freely provided through the UK National Health Service [NHS]) [38], in an attempt to better support those who have experienced ACEs and other childhood traumas and to break intergenerational cycles of harm and prevent offspring being exposed to adversity. At present, the ACE agenda is only beginning to be developed in an antenatal or midwifery context in the UK [39], and it is unclear if and how an understanding of historic childhood adversity may be relevant for health services in identifying and supporting vulnerable mothers. It is therefore important that we continue to increase our understanding of how ACEs may be associated with pregnancy outcomes.

\section{Methods}

\section{Study aim, design, setting and data extraction}

This study aims to explore the relationship between a history of ACEs and preterm birth among mothers engaged with health visiting services in south and west Wales. To our knowledge this is the first study to explore the associations between preterm birth and ACEs in a UK sample and furthers the evidence base on this topic through its examination of the role of maternal chronic health conditions on this relationship. Secondary analysis was carried out on anonymised cross-sectional data extracted from three health visiting services in urban and rural locations in south and west Wales in 2019/20. The study population is female primary caregivers (herein referred to as 'mothers') for whom ACE and Healthy Child Wales Programme (HCWP) data were made available by the health visiting services (see Measures). Health visitors completed data collection with mothers during their routine six-week post-partum contact on their retrospective ACE exposure $(90.7 \%$ of those asked accepted to complete ACE enquiry). Information from the mothers' HCWP record was also extracted. All data collection forms were subsequently stored in the mother's paper file. Administrative assistants in each health visiting service ensured data collection forms contained no identifiable information (redacting if required) before scanning copies to the lead author using secure NHS sharing platforms. Data were entered manually by the research team into SPSS v24 for cleaning and statistical analysis. All data entry was quality assured. Cases which were missing data on key demographic variables including age, ethnicity and preterm birth $(n=49)$ were removed from the sample, leaving a final sample for analysis of 865 .

\section{Measures}

\section{HCWP data - demographics and health}

Data were extracted from the HCWP on mothers' age, split into three discrete age categories $(16-25 ; 26-35$; $\geq 36$ years). Owing to its protected category status under General Data Protection Regulation (GDPR), mothers were asked by their health visitor to indicate their ethnicity using only a dichotomous variable ('white British' or 'Other'). In Wales, residential areas with higher deprivation are eligible for additional early years support services, in the form of Flying Start. Funding for Flying Start is allocated according to the estimated number of 0-3 year olds living in income benefit households in lower super output areas (LSOAs) of local authority areas. In 2018-19, over 36,000 children in Wales benefitted from Flying Start [40], which is used here as a proxy for deprivation. Mothers were also identified as living in Swansea, Carmarthenshire or Blaenau Gwent. HCWP data collection forms identified first-time mothers (first child: yes/no), preterm birth (i.e. birth before 37 completed weeks of gestation: yes/no) and provided data on relationship/marital status using the following categories: single (including separated, divorced or widowed); partnered/cohabiting; married; not disclosed. Further data were provided on mothers' identified gender and sexual orientation, but were not included in analyses due to small numbers $(<5)$ within some categories.

As part of the 6 weeks post-partum contact, health visitors routinely complete the Family Resilience Assessment Instrument and Tool (FRAIT). The FRAIT uses a series of questions and scales to assist health visitors in making robust, consistent and reliable assessments of family resilience and in identifying the support and interventions needed to help families to deal with adversity [41]. The tool is split into five subscales, one of which (Family Health) is used to identify the mother's chronic health conditions. The subscale is scored from one to five, with one representing parental chronic health problems that have a constant impact on the child's needs, and five describing parents with no chronic health issues. For the purposes of analyses here, a FRAIT score of 1-4 was used to identify mothers with one or more chronic health condition(s).

\section{Adverse childhood experiences (ACEs)}

Health visiting services providing data for this secondary analysis were those that had previously used a simplified version of established ACE questions from the Centers for Disease Control and Prevention short ACE tool [42] to retrospectively measure caregivers' childhood exposure (before they were 18 years of age) to the following ten ACE types: verbal abuse; physical abuse; sexual abuse; neglect; witnessing domestic violence; parental separation or divorce and parental/caregiver/household member mental illness; alcohol abuse; substance abuse; or incarceration. Mothers self-completed a written ACE questionnaire, alone or with the support of their health visitor if requested (e.g. when mothers had poor literacy), indicating yes/no to each ACE. For the purposes of 
analysis, mothers' overall ACE exposure was categorized into $0,1,2-3$ and $\geq 4$ ACEs; as is consistent with methodologies applied elsewhere $[19,21]$. These categories are intended to illustrate potential differences in outcomes by level of ACE exposure and current evidence does not identify them as having practical application for screening or intervention within health visiting services.

\section{Statistical analysis}

Analyses used chi squared tests for initial bivariate examination of the relationships between ACEs and preterm birth. Binary logistic regression was also used to examine the independent contributions of ACEs and demographics (age; ethnicity; Flying Start; area; first child; relationship status) to these outcomes. Three separate models were run to explore the effects of individual ACE types (Model 1), total ACE exposure (Model 2) and all ACE measures together (Model 3). Generalized Linear Models (GLMs) allow covariate and categorical variables to be fitted to dependent variables and the resultant model can be used to generate estimates for the dependent variable for given values of the independent variable [43]. GLMs were used to generate adjusted means (i.e. estimated marginal means [EMMs], taking into account demographic differences between individuals; e.g. age, ethnicity and deprivation) for preterm birth for individuals with different levels of ACE exposure. Sub-analyses were also conducted to compare the modelled estimates of the impact of ACEs on preterm birth for mothers with and without chronic health conditions.

\section{Results}

Over $60 \%$ (64.3\%) of mothers in the study population were aged $26-35$ years, with just under a quarter $(23.0 \%)$ aged 16-25 years. Married (31.0\%) and partnered/cohabiting mothers (39.3\%) made up the majority of the sample, although around one in every five $(21.4 \%)$ mothers chose not to disclose their relationship status. Reflective of the overall ethnic diversity of the adult population of Wales [44], $90.8 \%$ of sampled mothers identified as white British. Over a quarter (27.9\%) of mothers were in receipt of Flying Start services - representing the more disadvantaged areas of Wales. Overall, mothers had a mean of 1.8 children $(\mathrm{SD}=0.97)$, with first time mothers accounting for just under half (46.8\%) of the sample and only $2 \%$ of mothers having had a multiple birth (i.e. the birth of more than one infant from a single pregnancy). Of mothers in this sample, $4.7 \%$ had given birth (for the child[ren] they were currently receiving health visitor contact regarding) before 37 weeks gestation (preterm birth; Table 1).
Table 1 Associations between ACE exposure, demographics and preterm birth

\begin{tabular}{|c|c|c|c|}
\hline & \multicolumn{2}{|c|}{ Total sample } & \multirow{2}{*}{$\begin{array}{l}\text { Preterm birth } \\
\%\end{array}$} \\
\hline & $\mathbf{N}$ & $\%$ & \\
\hline All & 865 & - & 4.7 \\
\hline \multicolumn{4}{|l|}{ Total ACE exposure } \\
\hline 0 ACES & 408 & 47.2 & 3.9 \\
\hline $1 \mathrm{ACE}$ & 213 & 24.6 & 3.3 \\
\hline 2-3 ACES & 134 & 15.5 & 5.2 \\
\hline$\geq 4$ ACEs & 110 & 12.7 & 10.0 \\
\hline$x^{2}$ & & & 8.412 \\
\hline$p$ & & & 0.038 \\
\hline \multicolumn{4}{|l|}{ Age category (years) } \\
\hline $16-25$ & 199 & 23.0 & 3.0 \\
\hline $26-35$ & 556 & 64.3 & 4.5 \\
\hline$>36$ & 110 & 12.7 & 9.1 \\
\hline$x^{2}$ & & & 5.996 \\
\hline$p$ & & & 0.050 \\
\hline \multicolumn{4}{|l|}{ Ethnicity } \\
\hline White British & 785 & 90.8 & 5.1 \\
\hline Other & 80 & 9.2 & 1.3 \\
\hline$x^{2}$ & & & 2.378 \\
\hline$p$ & & & 0.123 \\
\hline \multicolumn{4}{|l|}{ Pilot area } \\
\hline Swansea & 449 & 51.9 & 5.3 \\
\hline Carmarthenshire & 224 & 25.9 & 4.0 \\
\hline Blaenau Gwent & 192 & 22.2 & 4.2 \\
\hline$x^{2}$ & & & 0.763 \\
\hline$p$ & & & 0.683 \\
\hline \multicolumn{4}{|l|}{ Deprivation } \\
\hline Non-Flying Start & 624 & 72.1 & 4.3 \\
\hline Flying Start & 241 & 27.9 & 5.8 \\
\hline$x^{2}$ & & & 0.846 \\
\hline$p$ & & & 0.358 \\
\hline \multicolumn{4}{|l|}{ First child } \\
\hline No & 460 & 53.2 & 4.8 \\
\hline Yes & 405 & 46.8 & 4.7 \\
\hline$x^{2}$ & & & 0.004 \\
\hline$p$ & & & 0.950 \\
\hline \multicolumn{4}{|l|}{ Relationship status } \\
\hline Single & 72 & 8.3 & 6.9 \\
\hline Partnered/cohabiting & 340 & 39.3 & 5.9 \\
\hline Married & 268 & 31.0 & 3.7 \\
\hline Not disclosed & 185 & 21.4 & 3.2 \\
\hline$x^{2}$ & & & 3.279 \\
\hline$p$ & & & 0.351 \\
\hline
\end{tabular}

ACE Adverse childhood experience

\section{Maternal ACE exposure}

Half of all mothers sampled (52.8\%) reported that they had been exposed to one or more of the ten ACEs 
captured by the health visiting service, with $12.7 \%$ reporting high ACE exposure ( $\geq 4$ ACEs; Table 1$)$, in line with prevalence identified in national surveys [23]. Among this sample, ACE exposure differed significantly by age, with younger mothers (aged 16-25years) reporting higher ACE exposure $(17.6 \% \geq 4$ ACEs, compared with $11.9 \%$ of mothers aged $26-35$ and $8.2 \%$ of those aged 36 years and over; $\mathrm{X}^{2}=21.073, p=0.002$ ). Reported experience of measured childhood adversity was also more common among white British mothers (compared with all other ethnicities; $X^{2}=15.509, p=0.001$ ). Although no significant difference in ACE exposure was found by health visiting service/geographical area, mothers in Flying Start areas (i.e. from more disadvantaged areas in Wales) reported higher overall ACE exposure ( $\geq 4$ ACEs; $17.0 \%$, compared with $11.1 \%$ of non-Flying Start; $\chi^{2}=11.610$, $p=0.009)$ and a greater prevalence of the individual ACE types: physical abuse $\left(14.9 \%\right.$ vs $8.5 \% ; \chi^{2}=7.822$, $p=0.005)$, witnessing domestic violence $(18.7 \%$ vs $13.0 \%$; $\left.\mathrm{X}^{2}=4.525, p=0.033\right)$, household mental illness $(26.1 \%$ vs $19.1 \% ; \chi^{2}=5.232, p=0.022$ ), household alcohol abuse (19.1\% vs $12.5 \%$; $\left.X^{2}=6.143, p=0.013\right)$, household drug abuse $\left(7.9 \%\right.$ vs $4.5 \%$; $\left.\chi^{2}=3.904, p=0.048\right)$ and household member incarceration $\left(8.7 \%\right.$ vs $2.1 \% ; \chi^{2}=20.188$, $p<0.001)$.

\section{Individual ACEs and preterm birth}

Bivariate analyses revealed a significant positive association between mothers' historic experiences of all measured forms of child maltreatment (verbal, physical, sexual abuse and neglect) and subsequent preterm birth (see Additional Table A1). Further, prevalence of preterm birth was significantly higher among mothers who had grown up witnessing domestic violence in their childhood home, and those who lived with parents or caregivers that experienced mental health issues (see Additional Table A1). When controlling for socio-demographic characteristics in multivariate analyses, significant independent effects on preterm birth remained for experiences of childhood sexual abuse and neglect (Table 2; Model 1).

Supplementary analyses revealed that all individual ACE measures were highly correlated in this sample, as is reported elsewhere $[45,46]$ (see Additional Table A2). Therefore, further analyses considered levels of overall $\mathrm{ACE}$ exposure as a potential predictor of preterm birth.

\section{Total ACE exposure and preterm birth}

Mothers' overall exposure to adversity in childhood was significantly positively associated with preterm birth in bivariate analyses (Table 1). An independent effect of high ACE exposure remained when controlling for age and other socio-demographics in multivariate analyses, with mothers exposed to $\geq 4$ ACEs over two and half times more likely than those with no ACEs to have preterm birth (Table 2; Model 2). No independent effect of ethnicity or deprivation on preterm birth was found. Modelled proportions (EMMs) of mothers who had a preterm birth ranged from 3.5\% of those with no ACEs, to $9.6 \%$ among those experiencing high ACE exposure ( $\geq 4$ ACEs) in the first 18 years of life (adjusted for age, ethnicity and deprivation; Fig. 1).

\section{Preterm birth and maternal chronic health problems}

According to FRAIT data (see Methods), 15.7\% of sampled mothers had one or more chronic health problem(s). Due to the strong theoretical and evidenced links between ACEs and maternal health, and maternal health and preterm birth $[5,8,21]$, additional subanalyses were conducted using 'healthy' mothers with no known chronic health conditions only $(n=709)$. For this sample, a more pronounced significant relationship between overall ACE exposure and likelihood of preterm birth was revealed, with mothers exposed to $\geq 4$ ACEs almost four times more likely to have given birth preterm $(\mathrm{AOR}=3.89 ; 95 \% \mathrm{CI}=1.40-10.80 ; p=0.009$; see Additional Table A3). The adjusted prevalence of preterm birth by ACE exposure for healthy mothers, those with chronic health conditions and the whole sample is shown in Fig. 1.

\section{Discussion}

Being born before full gestation can have profound life course impacts. This study adds to a growing body of evidence which highlights the potential reproductive and perinatal impact of maternal childhood adversity [18]. In the first known exploratory analysis of its kind for mothers in the UK, evidence was found of an association between high ACE exposure and preterm birth, with almost one in ten mothers with $\geq 4$ ACEs giving birth before 37 weeks gestation. As with studies reported elsewhere $[45,46]$, experiences of individual ACEs among these new mothers are inter-correlated. Therefore, whilst it is not clear if total ACE burden or specific ACEs are most influential, in support of previous research exploring the impact of historic sexual violence [9, 47-50], findings revealed that mothers' experiences of childhood sexual abuse increased the likelihood of preterm birth almost four-fold. Existing evidence on the impact of the ACE type childhood neglect on reproductive and perinatal health is limited [51]. Nevertheless, mothers in this sample who reported experiences of neglect in childhood were actually over seven and a half times more likely to give birth prematurely, highlighting the importance of considering the totality of the maternal childhood experience. The strength of the relationship between ACEs and 
Table 2 Logistic regression of individual and total ACE exposure, demographics and their association with preterm birth

\begin{tabular}{|c|c|c|c|c|c|c|c|c|c|c|c|c|}
\hline & \multicolumn{4}{|c|}{ Model 1} & \multicolumn{4}{|c|}{ Model 2} & \multicolumn{4}{|c|}{ Model 3} \\
\hline & AOR & Low $\mathrm{Cl}$ & High Cl & $p$ & AOR & Low $\mathrm{Cl}$ & High Cl & $p$ & AOR & Low $\mathrm{Cl}$ & High Cl & $p$ \\
\hline \multicolumn{13}{|l|}{ ACE types } \\
\hline Verbal abuse & 1.10 & 0.27 & 3.74 & 0.989 & & & & & 1.57 & 0.34 & 7.29 & 0.566 \\
\hline Physical abuse & 0.88 & 0.24 & 3.25 & 0.849 & & & & & 0.94 & 0.25 & 4.02 & 0.994 \\
\hline Sexual abuse & 3.83 & 1.19 & 12.32 & 0.025 & & & & & 5.43 & 1.45 & 20.34 & 0.012 \\
\hline Neglect & 7.60 & 1.81 & 31.97 & 0.006 & & & & & 9.12 & 1.92 & 43.37 & 0.005 \\
\hline Parental separation & 0.75 & 0.35 & 1.60 & 0.456 & & & & & 1.36 & 0.40 & 4.52 & 0.642 \\
\hline Domestic violence & 1.78 & 0.63 & 4.98 & 0.276 & & & & & 2.78 & 0.76 & 10.14 & 0.122 \\
\hline Mental health & 1.41 & 0.62 & 3.23 & 0.416 & & & & & 2.27 & 0.70 & 7.29 & 0.170 \\
\hline Alcohol abuse & 1.15 & 0.42 & 3.17 & 0.787 & & & & & 1.53 & 0.48 & 4.92 & 0.474 \\
\hline Drug abuse & 0.40 & 0.08 & 2.03 & 0.269 & & & & & 0.39 & 0.07 & 2.14 & 0.278 \\
\hline Incarceration & 1.23 & 0.26 & 5.84 & 0.793 & & & & & 1.51 & 0.29 & 7.80 & 0.622 \\
\hline \multicolumn{13}{|l|}{ Total ACE exposure } \\
\hline 0 ACES & & & & & (ref) & & & 0.073 & (ref) & & & 0.630 \\
\hline $1 \mathrm{ACE}$ & & & & & 0.80 & 0.32 & 2.00 & 0.635 & 0.50 & 0.14 & 1.86 & 0.303 \\
\hline 2-3 ACES & & & & & 1.17 & 0.46 & 2.97 & 0.740 & 0.31 & 0.04 & 2.55 & 0.278 \\
\hline$\geq 4$ ACEs & & & & & 2.67 & 1.14 & 6.23 & 0.024 & 0.10 & 0.00 & 3.38 & 0.201 \\
\hline \multicolumn{13}{|l|}{ Age category (years) } \\
\hline $16-25$ & (ref) & & & 0.009 & (ref) & & & 0.011 & (ref) & & & 0.008 \\
\hline $26-35$ & 1.94 & 0.72 & 5.21 & 0.190 & 2.21 & 0.85 & 5.74 & 0.103 & 1.96 & 0.72 & 5.33 & 0.187 \\
\hline$>36$ & 5.48 & 1.72 & 17.50 & 0.004 & 5.48 & 1.76 & 17.06 & 0.003 & 5.69 & 1.76 & 18.41 & 0.004 \\
\hline \multicolumn{13}{|l|}{ Ethnicity } \\
\hline Other & 0.17 & 0.02 & 5.21 & 0.098 & 0.22 & 0.03 & 1.66 & 0.142 & 0.19 & 0.02 & 1.54 & 0.121 \\
\hline \multicolumn{13}{|l|}{ Pilot area } \\
\hline Swansea & (ref) & & & 0.390 & (ref) & & & 0.476 & (ref) & & & 0.341 \\
\hline Carmarthenshire & 0.61 & 0.25 & 1.39 & 0.237 & 0.63 & 0.28 & 1.41 & 0.261 & 0.57 & 0.25 & 1.32 & 0.190 \\
\hline Blaenau Gwent & 0.64 & 0.26 & 1.55 & 0.321 & 0.72 & 0.31 & 1.68 & 0.450 & 0.64 & 0.26 & 1.55 & 0.324 \\
\hline \multicolumn{13}{|l|}{ Deprivation } \\
\hline Flying Start & 1.33 & 0.64 & 2.75 & 0.455 & 1.32 & 0.66 & 2.65 & 0.413 & 1.30 & 0.65 & 2.58 & 0.458 \\
\hline \multicolumn{13}{|l|}{ First child } \\
\hline Yes & 1.28 & 0.64 & 2.54 & 0.483 & 1.20 & 0.62 & 2.33 & 0.590 & 1.30 & 0.65 & 2.58 & 0.458 \\
\hline \multicolumn{13}{|l|}{ Relationship status } \\
\hline Single & (ref) & & & 0.593 & (ref) & & & 0.337 & (ref) & & & 0.595 \\
\hline Partnered/cohabiting & 1.02 & 0.34 & 3.08 & 0.98 & 0.90 & 0.31 & 2.57 & 0.837 & 1.00 & 0.33 & 3.02 & 0.997 \\
\hline Married & 0.67 & 0.19 & 2.38 & 0.54 & 0.51 & 0.16 & 1.70 & 0.275 & 0.67 & 0.19 & 2.34 & 0.527 \\
\hline Not disclosed & 0.55 & 0.15 & 2.06 & 0.38 & 0.44 & 0.12 & 1.58 & 0.208 & 0.37 & 0.15 & 2.04 & 0.208 \\
\hline
\end{tabular}

Model 1 = Individual ACEs, Model $2=$ Total ACE exposure, Model $3=$ Individual ACEs and total ACE exposure. Reference categories for dichotomous variables: white British ethnicity; non-Flying Start; has other children (first child = no)

ACE Adverse childhood experience, AOR Adjusted odds ratio, CI Confidence interval, Ref Reference category

preterm birth among mothers without known chronic health conditions, as identified in this analysis, warrants particular attention, as it underlines the potential importance of maternal mental health and wellbeing, which may be hidden harms in parturition. Individuals with known health conditions will often have received treatment addressing symptoms and also, in some cases, underlying physical and mental issues relating to their condition. Such issues are also associated with greater exposure to ACEs [21]. Here, we found a stronger relationship between ACEs and preterm birth in individuals with no other reported health issues. This finding needs further study. However, it may be related to less general support and intervention being provided to those yet to be diagnosed with a health condition or diagnosed health conditions potentially related to ACE exposure confounding statistical relationships directly between ACEs and preterm birth. 


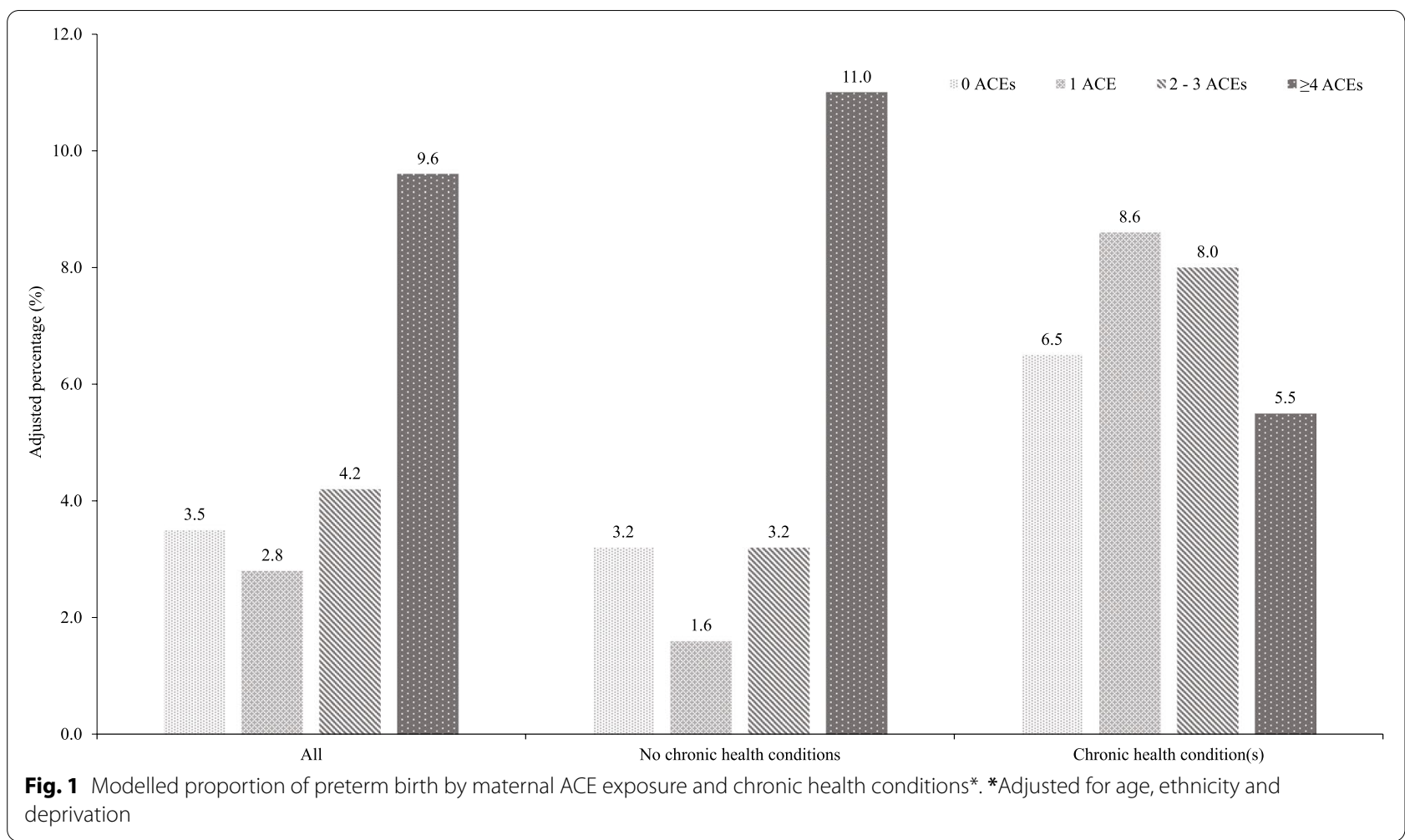

Experiencing ACEs in childhood can have developmental and behavioural consequences, both of which may be linked with preterm birth. When chronic stress overcomes resilience, activation of inflammatory processes and neuroendocrine responses (e.g. cortisol and epinephrine) that would normally maintain homeostasis can have a negative effect on the body, resulting in increased risk of impaired health and disease processes, including preterm birth [24, 52]. Prolonged stress can lead to changes in the brain, uterus and placenta, impacting the mechanisms involved in preparation for, and timing of, parturition [24, 53]. Maltreatment in childhood is associated with structural deficits in brain structure, function and connectivity [54] - abnormalities that are related to a range of mental health sequelae, such as depression and anxiety [52] - prenatal maternal risk factors for preterm birth [55-57]. Disrupted development and neurocognitive deficits also increase vulnerability for social and behavioural difficulties [58]. Thus, ACEs and other chronic stressors are strongly associated with a range of behaviours - often construed as 'coping mechanisms' [59] - that are harmful to both mother and infant and may mediate the relationship between adversity and preterm birth, such as smoking [60] and alcohol use during pregnancy $[61,62]$.

In a population with such hidden harms, the value of understanding an individuals' history of childhood adversity as a potential predictor for health impacts including preterm birth, and thus providing direction for targeted support or intervention, requires further consideration. In many health systems, midwifery services already routinely enquire about forms of victimization such as domestic violence and female genital mutilation [63, 64], with available evidence suggesting that practitioners perceive value in these processes $[65,66]$, although barriers to delivery remain [67]. Approaches to asking mothers about their experiences of childhood adversity have also been piloted in prenatal care in the US [68] and postnatally with health visiting services in the UK [38], where initial findings support both the feasibility and acceptability of such models, although impacts are less well established [69]. As ACEs occur in the context of care-giving relationships, these historic experiences may make it difficult for mothers to build and maintain trusting relationships with midwifery services [70], compounded by the relationship between early adversity and challenges such as being triggered by physical examination, fear of childbirth and delivery difficulties [47]. Therefore any model of enquiry for ACEs and associated childhood trauma should be developed and delivered in conjunction with wider principles of trauma-informed care and facilitate access to trauma-specific interventions (e.g. tailored labour planning) where required [71]. 
It is important to note that not all individual ACEs showed an independent relationship with preterm birth, and many mothers with a history of ACEs gave birth at full gestation, highlighting that the relationship between early adversity and preterm birth is by no means deterministic. However, approaches to identifying ACEs may have universal benefits when working with families in the early years, to break known intergenerational cycles of adversity and help to prevent exposure to ACEs and associated risk of preterm birth in subsequent generations. Such work has the potential to not only support families during the critical period of the first thousand days for bonding, attachment and building resilience [72, 73], but also reduce demands on healthcare, with the total annual cost of preterm birth to the public sector in England and Wales estimated at over $£ 2.9$ billion [74]. ACE-informed approaches delivered antenatally may add a new dimension where countries or regions are already forging an ACE awareness framework for practitioner training and screening (e.g. California [75]) and may have even greater application in countries where rates of preterm birth are higher and support for mothers and preterm infants is less readily available.

\section{Limitations}

Findings from this exploratory analysis should be interpreted in light of the following limitations. Firstly, prevalence of preterm birth identified in this sample is lower than national figures derived from the same time period $(7.8 \%$ [2]). As the sample only includes mothers who were actively engaged with a health visitor at 6 weeks post-partum, it may under-sample mothers whose infants have more complex care needs (i.e. were in special care baby units at 6-weeks post-partum), who experienced a still birth, or whose infant did not survive to 6 weeks post-partum, outcomes which may be more likely among preterm births. The present sample may also under-sample mothers who were identified by midwifery services as high risk and therefore may have health visitor contacts at different timings, meaning the opportunity to ask about ACEs did not arise. Secondly, the voluntary provision of self-reported ACE information may introduce a source of bias based on mothers' willingness to report ACEs to their health visitor and have such information retained within their health record. Just under one in ten who were offered ACE screening declined to participate and it was not possible to identify or exclude any bias created by non-participation. As in previous national surveys of ACEs, the retrospective nature of self-reporting also introduces the potential of recall bias, particularly for experiences that may have been repressed. Currently, there is insufficient data to understand whether experiencing a preterm birth may have an impact on recall and reporting of ACEs. Limited detail was provided on maternal health and such data is collected through health visitor assessment and not determined in conjunction with the mother, thus, may not take account of all relevant aspects of maternal health, particularly those that are less visible, thus also introducing a potential source of bias. No data were provided by health visiting services on health-harming behaviours such as prenatal maternal diet and alcohol consumption, which have known relationships with preterm birth. Data were also not available on a number of other potentially important covariates, including age of menarche. We took into account deprivation using flying start eligibility. However, there may still be relationships with childhood SES which we could not control for and further studies should seek to include a better measure of SES. Finally, in line with other research [76], our analysis included both individual and cumulative measures of ACEs (see model 3). However, strong relationships between these measures should be acknowledged in the interpretation of these findings. In spite of these limitations, which are inherent in a small-scale exploratory analysis of secondary data, these initial novel findings are important for generating interest in the potential relevance of an ACEs framework in antenatal care and helping to frame future research questions in this space.

\section{Conclusions}

The prevalence of ACEs retrospectively self-reported by mothers in this sample echoes that of adults in other primary health settings and national surveys, supporting the established premise that childhood adversity is not rare, and that experiences of different forms of victimisation or household dysfunction often co-occur. The widespread existence of ACEs in society highlights the need to consider different approaches to support those who have experienced childhood adversity across a variety of settings. With high ACE exposure associated with an increased risk of preterm birth as much as four fold among healthy mothers with no chronic health conditions, additional research is needed to explore this association in more detail, including the balance of influence for individual and cumulative ACEs on perinatal outcomes. Maternity and other services that engage with families during critical periods of child development may be uniquely placed, not only to offer trauma-sensitive support to deal with the impacts of ACEs and potentially mitigate some of the risks of early parturition, but also to help break cycles of adversity and health and social consequences for future generations. 


\section{Abbreviations}

ACE: Adverse childhood experience; AOR: Adjusted odds ratio; Cl: Confidence interval; EMM: Estimated marginal means; FRAIT: Family Resilience Assessment Instrument and Tool; GDPR: General Data Protection Regulation; GLM: Generalized linear model; HCWP: Healthy Child Wales Programme; LSOA: Lower super output area; REF: Reference category; SES: Socioeconomic status.

\section{Supplementary Information}

The online version contains supplementary material available at https://doi. org/10.1186/s12884-022-04454-z.

Additional file 1: Table A1. Bivariate association between individual ACEs and preterm birth.

Additional file 2: Table A2. Inter-correlations between individual ACEs.

Additional file 3: Table A3. Logistic regression of ACE exposure, demographics and their association with preterm birth among healthy* mothers.

\section{Acknowledgements}

The authors extend their sincere thanks to Natasha Judd, Katie Cresswell and Caspar Wynne for their support with data entry and cleaning.

\section{Authors' contributions}

$\mathrm{KH}$ conceived the research question, analysed and interpreted the data and produced the manuscript. KF and MB supported data interpretation and were both major contributors in writing the manuscript. All authors read and approved the final manuscript.

\section{Funding}

No funding was received for this research

\section{Availability of data and materials}

The data that support the findings of this study are available from the health visiting services in south and west Wales, but restrictions apply to the availability of these data, which were used under license for the current study, and so are not publicly available. Data are however available from the authors upon reasonable request and with permission of the health visiting services in south and west Wales.

\section{Declarations}

\section{Ethics approval and consent to participate}

All service users provided informed consent for ACE enquiry and all methods were carried out in accordance with relevant guidelines and regulations. Approval and ethical advice for use of anonymous data collected and held by health visiting services was requested and provided by the Research Governance committee in Public Health Wales. The study protocol was also scrutinised by the local Research and Development committees within each of the health boards responsible for the health visiting services. All committees agreed to secondary use of data for academic publication.

\section{Consent for publication}

Not applicable.

\section{Competing interests}

The authors declare that they have no competing interests.

\section{Author details}

${ }^{1}$ Policy and International Health, World Health Organization Collaborating Centre on Investment for Health and Well-being, Public Health Wales, Wrexham Technology Park, Wrexham LL13 7YP, UK. ${ }^{2}$ Public Health Collaborating Unit, School of Medical and Health Sciences, Bangor University, Wrexham Technology Park, Wrexham LL13 7YP, UK.

Received: 24 May 2021 Accepted: 2 February 2022

Published online: 16 February 2022
References

1. Platt MJ. Outcomes in preterm infants. Public Health. 2014:128(5):399-403.

2. Office for National Statistics. Birth characteristics in England and Wales: 2019. 2020. https://www.ons.gov.uk/peoplepopulationandcommunity/ birthsdeathsandmarriages/livebirths/bulletins/birthcharacteristicsineng landandwales/2019. Accessed 11 May 2021.

3. United Nations Children's Fund. Levels and trends in child mortality: report 2017, estimates developed by the UN inter-agency group for child mortality estimation. New York: United Nations Children's Fund; 2017.

4. Fuchs F, Monet B, Ducruet T, Chaillet N, Audibert F. Effect of maternal age on the risk of preterm birth: a large cohort study. PLoS One. 2018:13(1):e0191002.

5. Torchin H, Ancel PY. Epidemiology and risk factors for preterm birth. J Gynecol Obstet Biol Reprod (Paris). 2016;45(10):1213-30.

6. Shah NR, Bracken MB. A systematic review and meta-analysis of prospective studies on the association between maternal cigarette smoking and preterm delivery. Am J Obstet Gynecol. 2000;182(2):465-72.

7. Torloni MR, Betran AP, Dahler S, Widmer M, Dolan SM, Menon R, et al. Maternal BMI and preterm birth: a systematic review of the literature with a meta analysis. J Matern Fetal Neonatal Med. 2009;22(11):957-70.

8. Vogel JP, Chawanpaiboon S, Moller A, Watananirun K, Bonet M, Lumbiganon P. The global epidemiology of preterm birth. Best Pract Res Clin Obstet Gynaecol. 2018;52:3-12.

9. Cammack AL, Hogue CJ, Drews-Botsch CD, Kramer MR, Pearce BD. Associations between maternal exposure to child abuse, preterm birth, and very preterm birth in young, nulliparous women. Matern Child Health J. 2019;23:847-57.

10. Wolke $D$, Johnson S, Mendonça M. The life course consequences of very preterm birth. Annu Rev Dev Psychol. 2019;1:69-92.

11. Melville JM, Moss TJM. The immune consequences of preterm birth. Front Neurosci. 2013. https://doi.org/10.3389/fnins.2013.00079.

12. Ream MA, Lehwald L. Neurologic consequences of preterm birth. Neurol Syst Dis. 2018. https://doi.org/10.1007/s11910-018-0862-2.

13. Moster D, Terje R, Markestad T. Long-term medical and social consequences of preterm birth. N Engl J Med. 2008;359:262-73.

14. De Jong M, Berheoven M, Van Baar AL. School outcome, cognitive function, and behavioural problems in moderate and late preterm children and adults: a review. Semin Fetal Neonatal Med. 2012;17:163-9.

15. Olsen JM. Integrative review of pregnancy health risks and outcomes associated with adverse childhood experiences. J Obstet Gynecol Neonatal Nurs. 2018:47(6):783-94.

16. Racine N, Plamondon A, Madigan S, McDonald S, Tough S. Maternal adverse childhood experiences and infant development. Pediatrics. 2018. https://doi.org/10.1542/peds.2017-2495.

17. Osofsky JD, Osofsky HJ, Frazer AL, Fields-Olivieri MA, Selby M, Holman $\mathrm{S}$, et al. The importance of adverse childhood experiences during the perinatal period. Am Psychol. 2021;76(2):350-63.

18. Sulaiman S, Premji SS, Tavangar F, Yim IS, Lebold M, Ali NA, et al. Total adverse childhood experiences and preterm birth: a systematic review. Matern Child Health J. 2021;25:1581-94. https://doi.org/10.1007/ s10995-021-03176-6.

19. Felitti VJ, Anda RF, Nordenberg D, Williamson DF, Spitz AM, Edwards VE, et al. Relationship of childhood abuse and household dysfunction to many of the leading causes of death in adults: the adverse childhood experiences (ACE) study. Am J Prev Med. 1998;14(4):245-58.

20. De Venter M, Demyttenaere K, Bruffaerts $R$. The relationship between adverse childhood experience and mental health in adulthood. A systematic literature review. Tijdschrift Psychiatr. 2013;55(4):259-68.

21. Hughes K, Bellis MA, Hardcastle K, et al. The effect of multiple adverse childhood experiences on health: a systematic review and meta-analysis. Lancet. 2017;2:e356-66.

22. Kelly-Irving M, Lepage B, Dedieu D, Bartley M, Blane D, Grosclaude P, et al. Adverse childhood experience and premature all-cause mortality. Eur J Epidemiol. 2013;28:721-34.

23. Bellis MA, Hughes K, Ford K, Hardcastle KA, Sharp CA, Wood S, et al. Adverse childhood experiences and sources of childhood resilience: a retrospective study of their combined relationship with child health and educational attendance. BMC Public Health. 2018. https://doi.org/ 10.1186/s12889-018-5699-8. 
24. Olson DM, Severson EM, Verstraeten BSE, Ng JWY, McCreary JK, Metz GAS. Allostatic load preterm birth. Int J Mol Sci. 2015;16(12):29856-74.

25. Lilliecreutz C, Larén J, Sydsjö G, Josefsson A. Effect of maternal stress during pregnancy on the risk for preterm birth. BMC Pregnancy Childbirth. 2016. https://doi.org/10.1186/s12884-015-0775-x.

26. Lima SAM, El Dib RP, Rodrigues MRK, Ferraz GAR, Molina AC, Neto CAP, et al. Is the risk of low birth weight or preterm labor greater when maternal stress is experienced during pregnancy? A systematic review and meta-analysis of cohort studies. PLoS One. 2018;13(7):e0200594.

27. Gillespie SL, Christian LM, Alston AD, Salsberry PJ. Childhood stress and birth timing among African American women: cortisoal as biological mediator. Psychoneuroendocrinology. 2017;84:32-41.

28. Christiaens I, Hegadoren K, Olson DM. Adverse childhood experiences are associated with spontaneous preterm birth: a case-control study. BMC Med. 2015. https://doi.org/10.1186/s12916-015-0353-0.

29. Chung EK, Nurmohamed L, Mathew L, Elo IT, Cyone JC, Culhane JF. Risky health behaviours among mothers-to-be: the impact of adverse childhood experiences. Acad Pediatr. 2010;10:245-51.

30. Matei A, Saccone G, Vogel JP, Armson AB. Primary and secondary prevention of preterm birth: a review of systematic reviews and ongoing randomized controlled trials. Eur J Obstet Gynecol Reprod Biol. 2019;236:224-39.

31. Daskalakis G, Goya M, Pergioliotis V, Cabero L, Kyvernitakis I, Antsaklis A, et al. Prevention of spontaneous preterm birth. Arch Gynecol Obstet. 2019;299:1261-73.

32. Georgiou HM, Di Quinzio MKW, Permezel M, Brennecke SP. Predicting preterm labour: current status and future prospects. Dis Markers. 2015. https://doi.org/10.1155/2015/435014.

33. Kaplan ZAO, Ozgu-Erdinc AS. Prediction of preterm birth: maternal characteristics, ultrasound markers and biomarkers: an updated overview. J Pregnancy. 2018. https://doi.org/10.1155/2018/8367571.

34. Davey M, Watson L, Rayner JA, Rowlands S. Risk scoring systems for predicting pretern birth with the aim of reducing associated adverse outcomes. Cochrane Database Syst Rev. 2015. https://doi.org/10.1002/ 14651858.CD004902.pub5

35. Garcia-Blanco A, Diago V, De La Cruz VS, Hervás D, Cháfer-Pericás C, Vento M. Can stress biomarkers predict preterm birth in women with threatened preterm labor? Psychoneuroendocrinology. 2017:83:19-24.

36. Suff N, Story L, Shennan A. The prediction of preterm delivery: what is new? Semin Fetal Neonatal Med. 2019;24(1):27-32.

37. Pachter LM, Lieberman L, Bloom SL, Fein JA. Developing a community-wide initiative to address childhood adversity and toxic stress: a case study of the Philadelphia ACED Task Force. Acad Pediatr. 2017;17(7):S130-5

38. Hardcastle K, Bellis MA. Health visitor enquiry about caregivers' adverse childhood experiences (ACEs): key learning from a pilot evaluation. Cardiff: Public Health Wales; 2021

39. Mortimore V, Richardson M, Unwin S. Identifying adverse childhood experiences in maternity services. Br J Midwifery. 2021;29(2):70-80.

40. Welsh Government. Flying Start summary statistics 2018-19. 2019. https://gov.wales/sites/default/files/statistics-and-research/2019-07/ flying-start-summary-statistics-april-2018-to-march-2019-279.pdf. Accessed 11 May 2021

41. Pontin D, Thomas M, Jones G, O'Kane J, Wilson L, Dale F, et al. Developing a family resilience assessment tool for health visiting/public health nursing practice using virtual commissioning, high-fidelity simulation and focus groups. J Child Healthc. 2020;24(2):195-206.

42. Centers for Disease Control and Prevention. Behavioural risk factor surveillance system ACE data. 2020. http://www.cdc.gov/violencepr evention/acestudy/ace brfss.html. Accessed 11 May 2021.

43. IBM Knowledge Centre. SPSS statistics 24.0.0 generalized linear models 2016. https://www.ibm.com/support/knowledgecenter/zh/SSLVMB_ 24.0.0/spss/advanced/idh_idd_genlin_typeofmodel.html. Accessed 11 May 2021.

44. Welsh Government. Equality and diversity statistics: 2017 to 2019. 2020. https://gov.wales/equality-and-diversity-statistics-2017-2019. Accessed 12 May 2021

45. Baglivio MT, Epps N. The interrelatedness of adverse childhood experiences among high-rusk juvenile offenders. Youth Violence Juvenile Justice. 2015;14(3):179-98.
46. Afifi TO, Salmon S, Garcés I Struck S, Fortier J, Taillieu T, et al Confirmatory factor analysis of adverse childhood experiences (ACEs) among a community-based sample of parents and adolescents. BMC Pediatr. 2020 https://doi.org/10.1186/s12887-020-02063-3.

47. Leeners B, Stiller R, Block E, Görres G, Rath W. Pregnancy complications in women with childhood sexual abuse experiences. J Psychosom Res. 2010;69(5):503-10.

48. Leeners B, Rath W, Block E, Görres G, Tschudin S. Risk factors for unfavorable pregnancy outcome in women with adverse childhood experiences. J Perinat Med. 2014;42:171-8. https://doi.org/10.1515/.jpm-2013-0003.

49. Margerison-Zilk CE, Strutz KL, Li Y, Holzman C. Stressors across the lifecourse and preterm delivery: evidence from a pregnancy cohort. Matern Child Health J. 2017:21(3):648-58.

50. Noll JG, Schulkin J, Trickett PK, Susman EJ, Breech L, Putnam FW. Differential pathways to preterm delivery for sexually abuse and comparison women. J Pediatr Psychol. 2007;32(10):1238-48.

51. Infurna MR, Reichl C, Parzer P, Schimmenti A, Bifulco A, Kaess M. Associations between depression and specific childhood experiences of abuse and neglect: a meta-analysis. J Affect Disord. 2016;190:47-55.

52. Teicher $\mathrm{MH}$, Anderson $\mathrm{CM}$, Ohashi $\mathrm{K}$, Khan A, McGreenery CE, Bolger EA et al. Differential effects of childhood neglect and abuse during sensitive exposure periods on male and female hippocampus. Neurolmage. 2018;169:443-52

53. Power ML, Schulkin J. Function of corticotrophin-releasing hormone in anthropoid primates: from brain to placenta. Am J Hum Biol. 2006;18:431-47.

54. Teicher MH, Samson JA, Anderson CM, Ohashi K. The effects of childhood maltreatment on brain structure, function and connectivity. Nat Rev Neurosci. 2016:17:652-66.

55. Bublitz MH, Stroud LR. Childhood sexual abuse is associated with cortisol awakening response over pregnancy: preliminary findings. Psychoneuroendocrinology. 2012;37:1425-30.

56. Rose MS, Pana G, Premii S. Prenatal maternal anxiety as a risk factor for preterm birth and the effects of heterogeneity on this relationship: a systematic review and meta-analysis. Biomed Res Int. 2016. https://doi. org/10.1155/2016/8312158.

57. Staneva A, Bogossian F, Pritchard M, Wittowski A. The effects of maternal depression, anxiety and perceived stress during pregnancy on preterm birth: a systematic review. Women Birth. 2015;28(3):179-93.

58. Spratt EG, Friedenberg SL, Swenson CC, LaRosa A, De Bellis MD, Macias $M M$, et al. The effects of early neglect on cognitive, language and behavioural functioning in childhood. Psychology. 2012;3(2):175-82.

59. Monnat SM, Chandler RF. Long-term physical health consequences of adverse childhood experiences. Sociol Q. 2015;56(4):723-52.

60. Smith MV, Gotman N, Yonkers KA. Early childhood adversity and pregnancy outcomes. Matern Child Health J. 2016;20(4):790-8.

61. Brunton R, Dryer R. Child sexual abuse and pregnancy: a systematic review of the literature. Child Abuse Negl. 2021. https://doi.org/10.1016/j. chiabu.2020.104802.

62. Currie CL, Sanders JL, Swanepoel LM, Davies CM. Maternal adverse childhood experiences are associated with binge drinking during pregnancy in a dose-dependent pattern: findings from the All Our Families cohort. Child Abuse Negl. 2020. https://doi.org/10.1016/j.chiabu.2019.104348.

63. Bacchus L, Mezey G, Bewley S, Haworth A. Prevalence of domestic violence when midwives routinely enquire in pregnancy. BJOG. 2004;111:441-5.

64. Baillot H, Murray N, Connelly E, Howard N. Addressing female genital mutilation in Europe: a scoping review of approaches to participation, prevention, protection, and provision of services. Int J Equity Health. 2018. https://doi.org/10.1186/s12939-017-0713-9.

65. Creedy DK, Baird K, Gillespie K. A cross-sectional survey of pregnant women's perceptions of routine domestic and family violence screening and responses by midwives: testing of three new tools. Women Birth. 2020;33(4):393-400.

66. Mezey G, Bacchus L, Haworth A, Bewley S. Midwives' perceptions and experiences of routine enquiry for domestic violence. BJOG. 2003;110(8):744-52

67. Henriksen L, Garnweidner-Holme LM, Thorsteinsen KK, Lukasse M. 'It is a difficult topic' - a qualitative study of midwives' experiences with routine antenatal enquiry for intimate partner violence. BMC Pregnancy Childbirth. 2017. https://doi.org/10.1186/s12884-017-1352-2. 
68. Flanagan T, Alabaster A, McCaw B, Stoller N, Watson C, Young-Wolff KC. Feasibility and acceptability of screening for adverse childhood experiences in prenatal care. J Women's Health. 2018;27(7):903-11.

69. Ford K, Hughes K, Hardcastle K, Di Lemma LCG, Davies AR, Edwards S, et al. The evidence base for routine enquiry into adverse childhood experiences: a coping review. Child Abuse Negl. 2019;91:131-46.

70. Cloitre M, Stolbach BC, Herman JL, Kolk BV, Pynoos R, Wang J, et al. A developmental approach to complex PTSD: childhood and adult cumulative trauma as predictors of symptom complexity. J Trauma Stress. 2009;22(5):399-408.

71. Sperlich M, Seng JS, Li Y, Taylor J, Bradbury-Jones C. Integrating traumainformed care into maternity care practice: conceptual and practical issues. J Midwifery Womens Health. 2017;62(6):661-72.

72. Ortiz R. Building resilience against the sequelae of adverse childhood experiences: rise up, change your life, and reform health care. Am J Lifestyle Med. 2019;13(5):470-9.

73. Woods-Jaeger BA, Cho B, Sexton CC, Slagel L, Goggin K. Promoting resilience: breaking the intergenerational cycle of adverse childhood experiences. Health Educ Behav. 2018;45(5):772-80.

74. Mangham LJ, Petrou S, Doyle LW, Draper ES, Marlow N. The cost of preterm birth throughout childhood in England and Wales. Pediatrics. 2009;123(2):e312-27.

75. State of California Department of Health Care Service. The ACES aware initiative. 2021. https://www.acesaware.org/about/ Accessed 12 May 2021.

76. Kessler RC, McLaughlin KA, Green JG, Gruber MJ, Sampson NA, Zaslavsky AM, et al. Childhood adversities and adult psychopathology in the WHO World Mental Health Surveys. Br J Psychiatry. 2010;197. https://doi.org/10 1192/bjp.bp.110.080499.

\section{Publisher's Note}

Springer Nature remains neutral with regard to jurisdictional claims in published maps and institutional affiliations.

- fast, convenient online submission

- thorough peer review by experienced researchers in your field

- rapid publication on acceptance

- support for research data, including large and complex data types

- gold Open Access which fosters wider collaboration and increased citations

- maximum visibility for your research: over $100 \mathrm{M}$ website views per year

At BMC, research is always in progress.

Learn more biomedcentral.com/submissions 